\title{
Caracterização física de dois substratos orgânicos para plantas e a estimativa da umidade por meio da reflectometria no domínio do tempo
}

\author{
Physical characterization of two organic substrates for plants and the estimate of water content through the \\ time domain reflectometry
}

\author{
Roger Manuel Mestas ValeroI Edson Eiji MatsuraII Anderson Luiz de Souza ${ }^{\text {III }}$
}

\begin{abstract}
- NOTA -
RESUMO

O crescente uso de substratos na produção agrícola e no cultivo em ambiente protegido, promove produção em grande escala. Nesse sentido, as caracterizações químicas, biológicas e físicas desses materiais se fazem necessárias à proposição e à avaliação de padrões de qualidade que devem preceder a sua comercialização. As propriedades físicas dos substratos influenciam no bom desenvolvimento da plantas, sobretudo, no manejo de irrigação, onde a compreensão da relação retenção de água e aeração é imprescindível. Para tanto, mostra-se necessário que também se determine o volume de água presente nos substratos utilizados. Nesse sentido, o uso da reflectometria no domínio do tempo (TDR) pode representar um avanço em estudos dessa natureza. Dessa forma, baseado na determinação das curvas de retenção de água, neste trabalho, foram feitas as caracterizações físicas de dois substratos orgânicos: casca de pinus e fibra de coco. Também foram ajustadas, para cada um dos substratos avaliados, uma curva de calibração, através da qual, por meio da técnica da TDR, estimou-se o seu conteúdo de água. De maneira geral, com exceção da densidade seca, os substratos em estudo apresentaram características físicas da relação ar-água muito semelhantes. Quando comparado com os valores obtidos

ABSTRACT

The increasing use of substrates on agricultural production and controlled environment has been promoting its large scale production. In this way, chemical, biological and physical characterizations of these materials are necessary to the quality standard proposal and evaluation which must precede its commercialization. High plants development has been influenced by substrates physical properties, mainly on irrigation handling, where understanding about water retention and pore aeration is essential. Water volume determination on substrates used during experiments has been necessary, and in this way the use of the Time Domain Reflectometry (TDR) can represent an advance about this kind of researches. Based on water retention curve determination, this research, has been carried on physical characterizations of two organic substrates: coconut fiber and pine bark substrates. Also, a calibration curve has been adjusted for each tested substrates, and through TDR technique was estimated the water content. In a general, except to the dry density, the tested substrates has showed similar characteristics about its water-air relation. In the range readily available water, for both tested substrates, the TDR technique has showed a good performance on the water content estimative, with a determination coefficient of 0.9319 to the pine barks and 0.9385 to the coconut fiber.
\end{abstract} pelo método gravimétrico, na faixa de água facilmente disponível, a técnica da TDR apresentou um bom desempenho na estimativa da umidade de ambos substratos apresentando um coeficiente de determinação de 0,9319 para a casca de pinus e de 0,9385 para a fibra de coco.

Palavras-chave: umidade, retenção de água, manejo de irrigação, TDR, substratos.
Key words: water content, water retention, irrigation management, TDR, substrates.

O termo substrato aplica-se a todo material sólido, natural, sintético, residual, mineral ou orgânico,

IConselho Integrado de Planejamento e Gestão, Área de concentração em Água e Solos, Faculdade de Engenharia Agrícola (FEAGRI), Universidade Estadual de Campinas (UNICAMP), Cidade Universitária Zeferino Vaz, Campinas, SP, Brasil.

"FEAGRI, UNICAMP, Cidade Universitária Zeferino Vaz , Campinas, SP, Brasil. E-mail: matsura@agr.unicamp.br. Autor para correspondência.

IIIFaculdade de Tecnologia de Tatuí (Fatec-Tatuí ), Centro Estadual de Educação Tecnológica Paula Souza, Tatuí, SP, Brasil 
distinto do solo que, colocado em um recipiente em forma pura ou em mistura, permite o desenvolvimento do sistema radicular e desempenha, primordialmente, papel de suporte para as plantas nele cultivadas, podendo ainda regular a disponibilidade de nutrientes e de água (ABAD \& NOGUERA, 1998).

Uma vez que, de uma maneira geral, as propriedades físicas de um dado substrato não podem ser facilmente modificadas, conhecê-las é muito importante para a sua caracterização (MILNER, 2001). Entre as propriedades físicas mais utilizadas, destacamse a densidade, a porosidade, o espaço de aeração e a disponibilidade hídrica.

A definição da granulometria do substrato e, conseqüentemente, as relações entre ar e água, permitem uma manipulação adequada e uma melhor adaptação às situações de cultivo (FERMINO, 2002). Os conceitos de espaço de aeração e água disponível estão alicerçados na curva de retenção de água. O espaço de aeração é caracterizado como volume de macroporos preenchidos com ar, em condições de saturação hídrica e após livre drenagem. Nas mesmas condições, á água disponível se refere aos microporos preenchidos com água (entre 10-100hPa). O conhecimento da curva de retenção de umidade de um determinado substrato permite ao produtor determinar a quantidade de água a ser aplicada para uma espécie vegetal específica, cultivada num determinado recipiente (FERMINO, 2002).

Em alguns sistemas agrícolas intensivos, é necessário realizar medidas do conteúdo de água do meio com uma freqüência maior que a diária, para realizar um manejo da irrigação de forma mais produtiva (GOLDHAMER et al., 1999). Nesse sentido, diferentes métodos foram desenvolvidos nos últimos anos para determinar a umidade em solos. No caso de substratos, tais métodos devem ser adaptados, a fim de que possam ser utilizados de maneira eficiente. Dentre os métodos existentes, a técnica da TDR desperta muito interesse, em razão da possibilidade de se obter, de forma automatizada, estimativas da umidade de um meio poroso em tempo real.

Assim, o objetivo neste trabalho foi determinarem-se as características físicas dos substratos casca de pinus e fibra de coco, pela determinação das respectivas curvas de retenção de umidade e avaliar, em condições de laboratório, o desempenho da técnica da TDR, na estimativa da umidade, nesses mesmos substratos.

Para tanto, o presente trabalho foi conduzido no Laboratório de Hidráulica, Irrigação e Drenagem da Faculdade de Engenharia Agrícola, UNICAMP, Campinas, SP. Os substratos estudados foram: a) casca de pinus (CP), substrato comercial tipo horta 1, b) fibra de coco (FC), substrato comercial Golden Mix tipo 80granulado.

Para o cálculo da densidade seca (DS), foi determinado o teor da matéria seca das amostras, pela secagem em estufa a $65^{\circ} \mathrm{C}$, por 48 horas ou até a estabilização de seu peso. Os valores das densidades secas foram determinados pela equação 1 , segundo a metodologia proposta por HOFFMANN (1970):

DS $\left(\mathrm{Kg}^{\mathrm{m}} \mathrm{m}^{3}\right)=\frac{\text { densidadeúmida }\left(\mathrm{Kg} \mathrm{m}^{3}\right) \text { matériaseca }(\%)}{100}$

Para a determinação da porosidade total (PT), espaço de aeração (EA), água facilmente disponível (AFD), água tamponante (AT), água disponível (AD) e capacidade de retenção de água (CRA), foram utilizadas curvas de retenção de água, nas tensões de 0, 10, 50 e 100hPa, conforme DeBOODT \& VERDONCK(1972).

As curvas de retenção de água dos substratos foram confeccionadas no laboratório por meio da placa extratora de Richard, obtendo-se a umidade $\theta\left(\mathrm{m}^{3} \mathrm{~m}^{-3}\right)$ com relação a tensões aplicadas preestabelecidas. Foram utilizados anéis de aço inoxidável (5,20cm de diâmetro e 5,00cm de altura), os quais tiveram a parte inferior tampada com tecidos de nylon, sendo preenchidos com substratos umedecidos, garantindo-se a sua homogeneização, em seguida, os anéis foram pesados.

Posteriormente, os substratos foram saturados com água destilada e repousaram por 24 horas para que todo o ar fosse expulso. A partir desse momento, foram aplicadas tensões crescentes, deixando atuar cada uma delas durante, aproximadamente, 48 horas, tempo necessário para a estabilização. Simultaneamente, o anel com o substrato foi pesado, determinando-se a umidade. Para dispor de um maior número de dados e mais informação também determinou-se a umidade nas tensões de 20 , 30, 40 e 75hPa. As curvas de retenção de água foram elaboradas a partir do ajuste dos valores de umidade volumétrica obtidos nos percentuais de água retida por tensão, ao modelo proposto por VAN GENUCHETN(1980).

Para a determinação da granulometria, foram utilizadas amostras de $100 \mathrm{~g}$ de substrato seco ao ar, colocada sobre um conjunto de peneiras, acoplado a um agitador mecânico e acionado durante três minutos a 240 agitações $\mathrm{min}^{-1}$. As malhas das peneiras empregadas foram 4,70, 2,00, 1,00, 0,50, e 0,25mm. Após a agitação, o material retido em cada peneira foi pesado e utilizado para calcular a porcentagem em relação ao 
peso da amostra (média de 3 amostras). O índice de granulometria (IG) foi obtido somando-se, de forma acumulativa, as percentagens (em massa) das partículas com diâmetro superior a 1mm (adaptação do método proposto por RICHARD et al., 1989). Os valores das percentagens (em massa) correspondentes a cada fração granulométrica permitiram calcular também a média geométrica do diâmetro das partículas (dg), de acordo com o proposto por NOGUERA (1999).

A estimativa da umidade pela técnica da TDR requer o ajuste de curvas de calibração através das quais, a partir de valores da constante dielétrica (Ka) lidos por um equipamento de TDR, possa se estimar a umidade do meio poroso de interesse. Assim, para cada um dos substrados estudados, procedeuse da seguinte forma: amostras do substrato foram secas ao ar e peneiradas em malhas de $4 \mathrm{~mm}$, sendo em seguida acondicionadas em seis colunas de PVC de $22,5 \mathrm{~cm}$ de altura e $10 \mathrm{~cm}$ de diâmetro interno. Posteriormente, foram saturadas por capilaridade durante 24 horas e, a partir de então, por intermédio de balança analítica, tiveram a sua massa registrada até que atingissem uma umidade próxima à água tamponante (umidade próxima a valores do ponto de murcha permanente). Conhecidos os pesos seco e úmido das colunas de substrato, para cada medição, determinaram-se as umidades gravimétricas. Posteriormente, esses valores foram multiplicados pelas respectivas densidades dos substratos nas colunas avaliadas. Simultaneamente aos registros das massas, utilizando-se uma sonda multihaste de $20 \mathrm{~cm}$ de comprimento, acoplada a um equipamento TDR Tektronix, modelo 1502C, foram feitas leituras de Ka. Encerrados estes procedimentos, segundo a metodologia proposta por TOPP et al. (1980), ajustouse, para cada substrato, uma curva de calibração.

Para avaliar o desempenho das curvas de calibração obtidas, utilizou-se o coeficiente de concordância (d), proposto por WILLMOTT et al.(1985), descrito pela equação 2. Os valores de “d” variam de zero, para nenhuma concordância, a 1, para a concordância perfeita.

$d=1-\left[\frac{\sum_{i=1}^{n}\left(\theta_{i}-\theta_{i}^{*}\right)^{2}}{\sum_{i=1}^{n}\left(\left|\theta_{i}^{*}-\Theta\right|+\left|\theta_{i}-\Theta\right|\right)^{2}}\right]$

em que: $n$ é o número total de observações; $\theta$ é a umidade dos substratos obtida experimentalmente $\left(\mathrm{cm}^{3} \mathrm{~cm}^{-3}\right), \Theta$ é a umidade dos substratos estimadas pelas respectivas curvas de calibração $\left(\mathrm{cm}^{3} \mathrm{~cm}^{-3}\right)$ e T é a média das umidades obtidas experimentalmente $\left(\mathrm{cm}^{3} \mathrm{~cm}^{-3}\right)$.

A densidade seca obtida para os substratos avaliados foi de $233,7 \mathrm{~kg} \mathrm{~m}^{-3}$ para o CP e de $95,55 \mathrm{~kg} \mathrm{~m}^{-3}$ para o FC. Tais valores foram inferiores aos considerados como referências para um substrato hortícola (400-500 $\left.\mathrm{kg} \mathrm{m}^{-3}\right)$, (BUNT, 1988). As porosidades totais (PT) associadas aos substratos CP e FC foram, respectivamente, de 0,78 e $0,79 \mathrm{~m}^{3} \mathrm{~m}^{-3}$, valores que, de acordo com De BOODT et al.(1974), também estão abaixo da referência.

O espaço de aeração (EA), obtidos para CP e FC $\left(0,22\right.$ e $0,19 \mathrm{~m}^{3} \mathrm{~m}^{-3}$, respectivamente), estão próximos aos de referência $\left(0,20-0,30 \mathrm{~m}^{3} \mathrm{~m}^{-3}\right)$, sugeridos por De BOODT et al. (1974), embora BUNT (1973) tenha sugerido valores na faixa 0,10 e $0,15 \mathrm{~m}^{3} \mathrm{~m}^{-3}$, deve-se ressaltar que a escolha de um material com determinado valor de espaço de aeração está condicionada à espécie vegetal, estágio de desenvolvimento e manejo de irrigação.

Com relação às características de disponibilidade de água (AD), os substratos CP e FC apresentaram valores de água facilmente disponíveis (AFD) de 0,18 e $0,20 \mathrm{~m}^{3} \mathrm{~m}^{-3}$, respectivamente, muito próximos à referência $\left(0,20-0,30 \mathrm{~m}^{3} \mathrm{~m}^{-3}\right)$ sugerida por De BOODT \& VEDONCK (1972). No entanto, os dois materiais analisados apresentaram valores de água disponível (AD) abaixo da referência $\left(0,50 \mathrm{~m}^{3} \mathrm{~m}^{-3}\right)$ sugerida por De BOODT et al. (1974). Quanto à característica de capacidade de retenção de água (CRA), os substratos em estudo apresentam valores próximos de água retida em todas as tensões.

Os substratos avaliados apresentaram diferentes distribuições de tamanho de partículas, sendo que o FC apresentou, como fração mais abundante o intervalo granulométrico entre 2 e $0,5 \mathrm{~mm}$ com $62,40 \%$, enquanto na CP prevaleceram as partículas compreendidas entre 4,75 e $0,5 \mathrm{~mm}$ com $70,62 \%$.

Nas equações 3 e 4, constam as curvas de calibração obtidas para os substratos CP e FC, respectivamente. Os coeficientes de concordância a eles associados foram 0,948 e 0,953.

$\theta=-0,3853+0,1061 K a-0,004 K a^{2}+0,00005 K a^{3}$ $\theta=-0,2388+0,0801 K a-0,0026 \mathrm{Ka}^{2}+03,00003 \mathrm{Ka}^{3}$ em que: $\theta$ é a umidade dos substratos $\left(\mathrm{cm}^{3} \mathrm{~cm}^{-3}\right)$ e Ka é a constante dielétrica.

Com exceção da densidade seca, os substratos avaliados neste trabalho, casca de pinus e fibra de coco, apresentaram característica físicas da relação ar-água muito semelhantes e favorável a sua utilização como meio suporte para cultivo. A decisão de utilizá-los em uma mistura deve basear-se nas exigências da espécie que se deseja cultivar e nas características dos demais componentes da mistura.

Tomando-se como base os valores do índice de concordância (d), verifica-se que, para ambos substratos avaliados, as estimativas da umidade obtidas pelo uso da técnica de TDR foram satisfatórias 
indicando o potencial de uso desta técnica nos diferentes estudos que envolvam a determinação da umidade em substratos.

\section{AGRADECIMENTOS}

Às empresas de substrato Amafibra e Mec Prec pelo fornecimento do material para análise.

\section{REFERÊNCIAS}

ABAD, M.; NOGUERA, P. Substratos para el cultivo sin suelo y fertirrigación. In: CADAHIA, C. (Ed.). Fertirrigación: cultivos hortícolas y ornamentales. Madrid: Mundi-Prensa, 1998. p.287-342.

DE BOODT et al. Method for measuring the water release curve of organic substrates. Acta Horticulturae, Wageningen, v.37, p.2054-2062, 1974.

DE BOODT, M.; VERDONCK, O. The physical properties of the substrates in horticulture. Acta Horticulturae, Wageningen, v.26, p.37-44, 1972.

BUNT, A.C. Principles of nutrition Media and mixes for container-grown plants. London: Unwin and Hyman,1988. Cap.4. 309p.

BUNT, A.C. Some physical and chemical characteristics of loamless pot-plant substrates and their relation to plant growth. Plant and Soil, The Hague, n.38, p.1954-1965, 1973.

FERMINO, M.H. O uso da análise física na avaliação da qualidade de componentes e substratos. In: FURLANI, A.M.C. et al. Caracterização, manejo e qualidade de substratos para a produção de plantas. Campinas: Instituto Agronômico, 2002. p.29-37.
GOLDHAMER, D.A. et al. Sensitivity of continuous and discrete plant and soil water status monitoring in peach trees subjected to deficit irrigation. Journal of the American Society of Horticultural Science. Alexandria, v.124, p.437-444, 1999.

HOFFMANN, G. Verbindliche Methoden zur Untersuchung von TKS und Gartnerischen Erden. Mitteilubngen der VDLFA, Heft, v.6, p.129-153, 1970.

NOGUERA, P. Caracterización y evaluación agronómica del residuo fibra de coco: un nuevo material para el cultivo en sustrato. 1999. 228f. Tesis (Doctoral) - Universidad Politécnica de Valencia.

MILNER, L. Water and fertlizer management in substrates. In: INTERNATIONAL CONGRESS OF CITRUS NURSERYMEN, 6., 2001, Ribeirão Preto. Proceedings... Ribeirão Preto: ISCN, 2001. p.93-95.

RICHARDS, D. et al. The influence of particle-size distribution in pinebark:sand:brown coal protting nixes of water supply, aereation and plant growth. Scientia Horticulturae, Amsterdan. v.29, p.1-14, 1989.

TOPP,G.C.et al. Electromagnetic determination of soil water content: measurement in coaxial transmission lines. Water Resources Research, Washington, v.16, p.576-583, 1980.

VAN GENUCHTEN, M.T. A closed-form equation for predicting the hydraulic conductivity unsaturated soils. Soil Science Society American Journal, Madison, v.47, p.892898, 1980.

WILLMOTT,C.J. et al. Statistics for the evaluation and comparision of models. J ournal of Geophysical Research, Ottawa, v.90, n.C5, p.8995-9005, 1985. 